\title{
Use of a reproduction practice by a whole ear in winter wheat primary seed farming
}

\author{
Sergey Krivosheev ${ }^{1}$, Vasiliy Shumakov ${ }^{1}$, and Alexander Shumakov ${ }^{1}$ \\ ${ }^{1}$ Kursk Federal Agricultural Research Center 70b, Karl Marx St., Kursk, 305021, Russian Federation
}

\begin{abstract}
The article presents the results of field and laboratory studies from 2017 to 2020, on the basis of which a comprehensive assessment was given for the study of various sowing patterns $(2,3,4,5$ ears/run.m with a width of interspaces of $45 \mathrm{~cm}$ ) with a whole unfinished ear of winter soft wheat of the Lgovskaya 4 variety 4 in the nursery for testing offsprings of the first year in Kursk Region. It was found that when selecting whole ears by size, it is necessary to take into account the weight of grain in the ears, as the most variable feature. Inside the ear, a large density of plants was noted, which significantly reduced the nutritional area compared to the extreme plants in the ear. Plants inside the ear had similar conditions for nutrition and development in all sowing patterns. Extreme plants in the ear due to the larger food area were in better conditions. Productive bushiness decreased with thickening of crops with ears from 2.1 to 1.6 stems/plant. The density of the cenosis and yield, on the contrary, increased by $85 \%$ and $60.4 \%$, respectively. The best conditions for the formation of a full-value seed crop were developed at 4 ears/lin.m, since maximum indicators were noted: the survival rate of plants from the ears was $84.1 \%$, the yield of conditioned seeds was $93 \%$, the germination energy was $95 \%$, the smallest number of rejected families was $19 \%$. The use of a compacted sowing pattern of 4 ears/lin.m in the first-year offspring testing nursery increased seed yield by $75 \%$ compared to the control.
\end{abstract}

\section{Introduction}

Seed farming fulfills two main tasks - preservation of varietal and yield qualities of seeds when reproducing and providing grain producers with high-quality seeds in sufficient quantity at acceptable prices.

The work of the winter wheat seed farming system on the implementation of varietychanging and variety renovation is based on the production of original seeds. The scheme of primary seed production and obtaining original seeds depends on the selection method, which is its basis. It is recommended to use the method of individual-family selection with a double check for offspring for the production of elite seeds of selfpollinating and cross-pollinating crops [1].

In modern conditions, it is more often used for longterm use varieties in production conditions in order to maintain yield potential and variety purity $[2,3]$.

It should be taken into account that systematic intravarietal selection of the best plants in terms of productivity leads to a decrease in its adaptive capabilities [4]. An important role in improving the adaptive properties of the variety is played by the techniques of varietal management $[5,6]$.

The first two years of reproduction are characterized mainly by the selection and reproduction of typical and homogeneous in phenotype and genotypeplants.

Seeds of the best selected plants or whole unfinished ears left after laboratory sorting are used for laying the nursery for testing offspring of the first year. Whole ears are selected mainly from the main stem, and when selected by the whole plant, seeds from the stems of both the first and subsequent orders are used. Matrix variability is manifested in the formation of seeds on one plant. Seeds formed on the main stem are significantly better in terms of sowing and yield qualities than seeds obtained from stems of the second or subsequent orders [7]. When the seeds from the central part of the ear are sown, even with a decrease in the sowing rate by $30 \%$, selected seeds, due to the large number of grains in the ear and grain size, provide a higher yield [8].

Sowing of the breeding nursery with unfinished ears was proposed at the Research Institute of Agriculture named after V.V. Dokuchaev (Molokostova E.I., 1990) and Research Institute of Agriculture of Central Regions of Non-Chernozemic Zone (Sandukhadze B.I., 1995) [9].

Under the conditions of the Central Regions of the Non-Chernozemic Zone, one of the two methods of laying a nursery for testing the offspring of the 1 st year ofspring triticale, the method of sowing with unfinished ears turned out to be by an order of magnitude more effective for maintaining varietal purity, compared to the traditional method of sowing seeds, although less yielding [10].

When laying the breeding nursery of the first year of barley with unfinished ears, the labor intensity of plant selection and threshing decreased, the volume of work increased to 10 thousand families. In comparison with 23 rows sown by cassette seeder, the unfinished ear makes it possible to maximize the density of the plant standof the seed plot and, thus, to provide a more rigid sorting of the numbers by the resistance to disease and creeping [11]. 
To mechanize the process of sowing with ears and reduce labor costs in Don Zonal Research Institute of Agriculture a mounted breeding seeder SN-16 was converted in such a way as to make four working places for seeding workers. As a result, four workers provide sowing of 40-50 thousand ears for 2 days for the needs of selection and seed production. On one linear meter three ears were sown [9]. Sowing with an unfinished ear according to the $40 \times 45 \mathrm{~cm}$ scheme made it possible to increase the number of studied lines, save the area [12].

In Siberia nurseries for testing offspring of the first year of spring cereals were laid out according to the $40 \times 50$ $\mathrm{cm}$ scheme [13].

The selection efficiency in the breeding nursery of spring barley sown with whole ears was not inferior to the selection of lines sown with seeds. Three whole ears were placed on one square meter [14].

Thus, improving the technology of cultivation when sowing with whole ears is a task of high priority.

The aim of the study is to determine the optimal sowing pattern with a whole unfinishedear to increase the yield of seeds with high sowing qualities in the nursery for testing offspring of the first year of winter wheat.

\section{Objects and Methods}

The research was carried out in the field experiment of the Seed Farming Laboratory of the Federal State Budgetary Scientific Institution "Kursk Federal Agricultural Research Center" from 2017 to 2020. In the experiment, four patterns for sowing a nursery for testing offspring of the first year ( $\mathrm{P}-1)$ with a whole unfinished ear were studied. With a width of interspaces of $45 \mathrm{~cm}$ per 1 linear meter, ears were sown according to the following variants: 1) control -2 ears; 2) 3 ears; 3) 4 ears; 4) 5 ears.

The ears were selected in Nursery 1. When selecting, healthy, large, well-seeded ears were taken from plants with a typical bush shape, high productive bushiness, equalized stem stand, with characteristic of the variety height, general habitus and architectonics.

The studies were carried out on the local winter wheat varietyLgovskaya 4, widely distributed in Central Chernozem Region of Russia.

The predecessor is pure fallow. The tier of the experiment is the quadruple,the accounting area of the plot is $25 \mathrm{~m}^{2}$. The soil of the experimental plot is represented by typical thick heavy loamy chernozem. The content of humus in the arable horizon is $6.1 \%, \mathrm{P}_{2} \mathrm{O}_{5} 15.8$ $\mathrm{mg} / 100 \mathrm{~g}$ of soil (according to Chirikov method), $\mathrm{K}_{2} \mathrm{O}$ $11.7 \mathrm{mg} / 100 \mathrm{~g}$ of soil (according to Maslova method). The reaction of the soil medium is neutral $(\mathrm{pH} 7.0)$.

Mineral fertilizers were appliedinpresowing cultivation at a rate of $\mathrm{N}_{15} \mathrm{P}_{39} \mathrm{~K}_{39}$ and nitrogen foliar dressing with ammonium nitrate $\left(\mathrm{N}_{68}\right)$ was carried out in the spring tillering phase.

For the mechanization of sowing, the seeder SN-16 was converted according to the model designed in the Don Zonal Research Institute of Agriculture. The seeder consisted of 4 shovel openers, large-diameter seed tubes. Sowing was performed by four sowing workers.
In the process of vegetation, loosening of interspaces was carried out with a row crop cultivator equipped with one-sided razors and needle harrows. Protection of plants against diseases and pests was carried out with preparations recommended by the firm "Singenta".

During the vegetation period, records and observations were made using the state variety test methods (1989). Visual and laboratory assessment of the seed material was carried out according to the "Methodological recommendations for the production of elite seeds of grain, leguminous and cereal crops" (1990).

Harvesting was done manually. Each family from the ear was reaped with a sickle and tied into sheaves, and then threshed separately in a thresher. In the laboratory conditions, families were selected and sorted from a whole ear.

Mathematical processing of the data was carried out by the method of dispersion analysis as presented by B.A. Dospekhov.

The weather conditions during the vegetation of winter wheat varied significantly by month and year of study.

The weather conditions in the autumn period of 2017 were favorable for the growth and development of winter wheat. The air temperature in September and October was within the average summer norm, and the amount of precipitation was $109 \%$ of the norm. In the spring-summer period of 2018, plant vegetation took place at elevated temperatures and moisture deficiency (HTC in May-June amounted to 0.83-0.77). Heavy rainfall in July contributed to the germination of grain in the ear, which negatively affected the quality of the yield and the sowing properties of the seeds. In 2019, warm spring and sufficient moisture supply contributed to accelerated plant development. (HTC in May amounted to 1.60). In June grain formation and filling took place under the conditions of increased temperature regime and insufficient amount of precipitation $(\mathrm{HTC}=0.38)$. Heavy precipitation and a decrease in temperature in the first decade of July slowed down the onset of complete ripeness in winter wheat and the beginning of harvesting. In general, the spring-summer period was unfavorable for the formation of a high winter wheat yield. In April and May 2020 plants vegetated at high soil moisture content and low air temperatures (HTC in May amounted to 1.97). In June yield formation took place at elevated temperatures and sufficient humidification.

Heavy precipitation and reduced temperatures in the second decade of July contributed to the production of high wheat yields.

\section{Results and Discussion}

The quantitative characteristics of the seeded ears are shown in Table 1. When selected, the indicators "earlength" and "weight of 1000 grains" were less variable signs, since the coefficient of variation was $11.2 \%$ and $9.3 \%$, and the coefficient of equalization was $88.8 \%$ and $90.7 \%$, respectively. Maximum variability was observed in the indicator "grain weight in the ear," where it was $35.9 \%$, and the equalization coefficient was only $64.1 \%$. 
Thus, when selecting whole ears by size, it is necessary to take into account the weight of grain in the ears, as the most unstable sign, depending on the meteorological conditions of the growing season and the conditions of mineral nutrition. The selection according to the length and weight of the ear gives a more objective assessment than the selection according to one of these indicators and allows one to select ears with filled and large grain.

Table 1. Quantitative characteristics and coefficients of variation and equalization of seeded ears.

\begin{tabular}{|c|c|c|c|}
\hline Indicator & $\begin{array}{c}\text { Averagef } \\
\text { or } \\
2017- \\
2019\end{array}$ & $\begin{array}{c}\text { Coefficient } \\
\text { ofvariation } \\
, \mathrm{V}, \%\end{array}$ & $\begin{array}{c}\text { Equalizati } \\
\text { oncoeffici } \\
\text { ent } \%\end{array}$ \\
\hline $\begin{array}{c}\text { Ear length, } \\
\text { cm: } \\
\text { min-max } \\
\text { average }\end{array}$ & $\begin{array}{c}8-10 \\
8,8\end{array}$ & 11,2 & 88,8 \\
\hline $\begin{array}{c}\text { Number of } \\
\text { grains per } \\
\text { ear, pcs. } \\
\text { min-max } \\
\text { average }\end{array}$ & $\begin{array}{c}33-59 \\
44,7\end{array}$ & 29,1 & 70,9 \\
\hline $\begin{array}{c}\text { Grain } \\
\text { weight per } \\
\text { ear, g: } \\
\text { min-max } \\
\text { average }\end{array}$ & $\begin{array}{c}1,92-3,85 \\
2,66\end{array}$ & 35,9 & 64,1 \\
\hline $\begin{array}{c}\text { Weight of } \\
\text { 1000 grains, } \\
\text { g: }\end{array}$ & $54,5-65,3$ & 9,3 & 90,7 \\
$\begin{array}{c}\text { min-max } \\
\text { average }\end{array}$ & 59,3 & & \\
\hline
\end{tabular}

Wide inter-rows $(45 \mathrm{~cm})$ provided full lighting, which made it possible to thicken plants in rows. Families from the ear were separately standing bushes. The nutrition area of the ear bush was reduced from $2,300 \mathrm{~cm}^{2}$ in the control to $900 \mathrm{~cm}^{2}$ at maximum thickening (Table 2). On the average, the nutrition area of one plant in the control variant was 2.43 times higher than when thickened in 5 ears/lin.m.

Table 2. The effect of sowing density on the nutritional area of plants from a whole spike.

\begin{tabular}{|c|c|c|c|c|}
\hline \multirow[b]{2}{*}{$\begin{array}{c}\text { Number } \\
\text { of ears, } \\
\text { pes /lin. } \\
\text { m }\end{array}$} & \multicolumn{4}{|c|}{ Nutrition area, $\mathrm{cm}^{2}$} \\
\hline & $\begin{array}{l}\text { bush } \\
\text { from } \\
\text { the ear }\end{array}$ & $\begin{array}{l}1 \text { plant } \\
\text { from } \\
\text { the ear, } \\
\text { medium }\end{array}$ & $\begin{array}{c}1 \\
\text { extreme } \\
\text { plant }\end{array}$ & $\begin{array}{l}1 \text { plant in } \\
\text { the center }\end{array}$ \\
\hline 2 & 2300 & 98,6 & 225 & 11,3 \\
\hline 3 & 1500 & 64,2 & 129 & 11,3 \\
\hline 4 & 1200 & 46,6 & 84 & 11,3 \\
\hline 5 & 900 & 40,7 & 56 & 11,3 \\
\hline
\end{tabular}

Inside the ear, there was a high density of plants, which significantly reduced the nutritional area compared to extreme plants. Plants inside the spike had similar conditions for nutrition and development in all sowing patterns. Extreme plants in the ear due to the larger nutritional area were in better conditions.

Thus, plants inside the ear in all thevariants experienced difficulties in developmentdue to high density, and the best conditions were notedfor extreme plants, especially with thinned sowing patterns. Wide interspaces partially compensated for the small nutritional area of plants inside the ear and contributed to their normal development.

Despite the presence of a large number of plants in the bush, they were also subject to stressful factors, like plants sown by grains. Some plants became extinct during wintering, while others died due to drought due to insufficient development of the root system. On the average, over the years of research, the survival was 79.6$84.1 \%$ (Table 3). The optimal variant for this indicator was with four ears per linear meter.

Due to the high density of plants inside the bush, tillering was difficult in all the variants. However, due to extreme plants with a high nutritional area, the productive bushiness decreased in the whole slightly from 2.1 to 1.6 stems/plant during thickening of the crop with the ear.

The density of the cenosis of productive ears per area unit increased by $85 \%$ as crops thickened. When compared with a continuous sowing of 5 million/ha of germinating seeds, it did not reach the optimal value for the Lgovskaya 4 variety.

Table 3. Effect of sowing density on survival, productive bushiness, density of cenosis and yield of plants from a whole ear (2017-2020).

\begin{tabular}{|c|c|c|c|c|}
\hline $\begin{array}{c}\text { Numbe } \\
\text { r of } \\
\text { ears, } \\
\text { pcs. } \\
\text { m }\end{array}$ & $\begin{array}{c}\text { Survi } \\
\text { valrat } \\
\text { e, } \%\end{array}$ & $\begin{array}{c}\text { Produ } \\
\text { ctive } \\
\text { bushi } \\
\text { ness }\end{array}$ & $\begin{array}{c}\text { The density } \\
\text { of the cenosis, } \\
\text { (product. } \\
\text { ears, } \\
\text { pcs. } / \mathrm{m}^{2}\end{array}$ & $\begin{array}{c}\text { Yield, } \\
\text { t/ha }\end{array}$ \\
\hline 2 & 79,6 & 2,1 & 213 & 3,56 \\
\hline 3 & 81,8 & 1,9 & 296 & 4,51 \\
\hline 4 & 84,1 & 1,7 & 365 & 5,32 \\
\hline 5 & 80,0 & 1,6 & 393 & 5,71 \\
\hline LSD $_{05}$ & 2,1 & 0,2 & 29 & 0,42 \\
\hline
\end{tabular}

The yield varied within $3.56 \mathrm{t} / \mathrm{ha}$ in the control and up to $5.7 \mathrm{t} / \mathrm{ha}$ at maximum thickening. With an increase in the density of the cenosis of productive earsthe yields also increased.

An important indicator for seed crops was the yield of conditioned seeds. It reached a maximum value of $93 \%$ in the variant of 4 ears/lin.m, the percentage of seeds produced was minimum - $88.1 \%$ (Table 4 ). To estimate the yield of seed grain from anarea unit we used the capacity of the cenosis as an indicator. Among the sowing patterns, variants with 4 and 5 ears/lin.m stood out, where the excess over control was 61.2 and $70.7 \%$. The reproduction coefficient as crops thickened decreased from 34.8 in the control to 23.7 with maximum thickening.

Table 4. Effect of plant sowing density from the whole ear on the yield of conditioned seeds, the capacity of the cenosis and the reproduction coefficient (2018-2020). 


\begin{tabular}{|c|c|c|c|}
\hline $\begin{array}{c}\text { Number } \\
\text { of ears, } \\
\text { pcs. } \\
\text { /lin. } \mathrm{m}\end{array}$ & $\begin{array}{c}\text { Yieldofcon } \\
\text { ditionedsee } \\
\mathrm{ds}, \%\end{array}$ & $\begin{array}{c}\text { Seed grain } \\
\text { cenosis } \\
\text { capacity, } \\
\text { pcs/m } \mathrm{m}^{2}\end{array}$ & $\begin{array}{c}\text { Reprodu } \\
\text { ctionrate }\end{array}$ \\
\hline 2 & 88,1 & 6837 & 34,8 \\
\hline 3 & 90,3 & 9028 & 30,6 \\
\hline 4 & 93,0 & 11023 & 28,0 \\
\hline 5 & 91,2 & 11672 & 23,7 \\
\hline
\end{tabular}

Sowing properties of seeds characterize their suitability for sowing and storage. The weight of 1000 seeds in the experiment had little variability. The decrease was $3 \%$ (Table 5) with the maximumthickening. The main characteristic of the biological value of seeds is the energy of germination. It characterizes the level of ability of seeds in the field to give simultaneous and even seedlings. High germination energy was in seeds from the variant with 4 ears/lin.m - 95\%, which is $2-3 \%$ higher than in the control and in the variant with maximum thickening. Similar results are obtained for germination of seeds.

Table 5. Effect of the density of plants sown from a whole ear on the sowing qualities of seeds and the sorting of families (2018-2020).

\begin{tabular}{|c|c|c|c|c|}
\hline $\begin{array}{c}\text { Number } \\
\text { of ears, } \\
\text { pcs. /lin. } \\
\text { m }\end{array}$ & $\begin{array}{c}\text { Weight } \\
\text { of } 1000 \\
\text { seeds, g }\end{array}$ & $\begin{array}{c}\text { Germin } \\
\text { ationen } \\
\text { ergy, \% }\end{array}$ & $\begin{array}{c}\text { Germin } \\
\text { ationrat } \\
\text { e, \% }\end{array}$ & $\begin{array}{c}\text { Famili } \\
\text { esrejec } \\
\text { ted \% }\end{array}$ \\
\hline 2 & 46,1 & 93 & 94 & 27 \\
\hline 3 & 45,2 & 94 & 95 & 21 \\
\hline 4 & 45,1 & 95 & 96 & 19 \\
\hline 5 & 44,7 & 92 & 94 & 23 \\
\hline
\end{tabular}

In the process of vegetation, families to be removed during harvesting were noted: atypical, stunted and with signs of diseases. Under the laboratory conditions the harvest of families was evaluated after threshing by the weight and amount of grain, typicity, performance and equalization.

The largest percentage of rejected families was in the control and in the variantwith 5 ears/lin.m $-27 \%$ and $23 \%$. The low number of rejected families was noted in the variantwith 4 ears/lin.m - 19\%.

It is much more convenientto carry out rejection and harvestingfor separately located families from a whole ear, growing in the form of a bush, than for crops sown in rows.

\section{Conclusion}

Based on the results of the studies of winter soft wheat of Lgovskaya 4 variety, a pattern for sowing with whole ears with 4 ears/lin.m $(25 \mathrm{~cm} \mathrm{x} 45 \mathrm{~cm})$ or $8.8 \mathrm{pcs} / \mathrm{m}^{2}$ was recommended in the first-year offspring testing nursery.

With this sowing pattern, as a result of densification, compared with the control, the yield increased by $49.4 \%$, the yield of conditioned seeds by $4.9 \%$, the capacity of the seed grain cenosis increased by $61.2 \%$, the seed germination energy by $2 \%$, the number of rejected families decreased by $8 \%$.
Using a compacted seeding pattern of 4 earsper one linear meter in the first-year offspring testing nursery, the yield of high-quality seed material increased by $75 \%$ overall.

The work was carried out as part of the state task of the Federal State Budgetary Scientific Institution "Kursk Federal Agricultural Research Center" on the topic No. 0632-2019-0016 "Develop technologies for the production of seeds of higher reproductions of new winter wheat varieties".

\section{References}

1. Methodological recommendations for the production of seeds of the elite of grain, leguminous and cereal crops (All-Union Academy of Agricultural Sciences named after V.I. Lenin, Moscow, 1990)

2. T.I. Firsova Autoreferat of the dissertation of the Candidate of Agricultural Sciences Varietal and crop qualities of winter wheat in the primary links of seed production, depending on the methods of selecting elite plants (2006)

3. V.V. Novokhatin Achiev. Sci. \& Technol. Agribusiness 932 (2018)

4. J.J. Wiersma, R.H. Busch, G.G. Fulcher, Crop Sc. 4 $41(2001)$

5. M. Oberforster Klimaseminar, LFZ RaumbergGumpenstein Trockenheit-Herausforderungen fur die Zuchtung und den Anbau von Getreide 2623 (AGES Wien 4. 2009)

6. G. Podolska, A. Sulek, Polish J. of Agron. 11 (2012)

7. I.G. Stronai. General seed science of field crops. FROM 464 (1966)

8. D. Shpaar Cultivation, harvesting, refinement and use Grain cultures. FROM 654 (2012)

9. A.I. Grabovets, M.A. Fomenko Winter wheat. FROM 600 (2007)

10. E.V. Skatova. Triticale. Proc. Int. Sci. \& Pract. Conf. Don Zonal NIIS. Use of a method for sowing triticale of spring spikes in primary seed production of the Center of the Non-Black Earth Zone FROM 196 (2016)

11. L.M. Eroshenko, A.N. Eroshenko, M.M. Romakhin, N.A. Eroshenko Proc. III International Sci. \& Pract. Conf., Zonal NIIS of the Northeast Features of the selection process of spring barley FSBNU "Moscow NIISH" Nemchinovka." Methods and technologies in plant breeding and crop production 54 (2017)

12. E.V. Skatova, A.G. Lachin, Vladimir farmer 4 (2019)

13. N.G. Vedrov, I.V. Pentyukhov, N.V. Zobova Bull.KrasGAU 5 (2012)

14. Organizational and methodological basis of functioning of selection process of spring barley. Methodological recommendations. (2018) 